\title{
Enhancing the academic library experience with chatbots: An exploration of research and implications for practice
}

\author{
ABSTRACT \\ This paper explores the potential of using chatbots to improve the academic research \\ experience for university students with a literature based discussion reflecting on a \\ prototype being developed at the University of Technology Sydney (UTS). The paper \\ proposes that information professionals need to adapt emerging technologies such as \\ chatbots to innovate, improve and support library services. Designing a positive \\ experience for the user is essential to ensure that such technological solutions are \\ sustainable. In this exploratory paper, we argue that it is important that librarians \\ engage with the conversational design of the library chatbot in collaboration with the \\ technology developers in order to make it useful, friendly, trustworthy, and \\ customisable for university students.
}

Keywords: chatbots, research, libraries, information services, automation, higher education 


\section{INTRODUCTION AND BACKGROUND}

This paper explores the potential of enhancing the undergraduate academic research experience via conversational agents and is based on a pilot study and prototype in development. Commonly known as chatbots, features of such conversational agents or communicative technologies, include user-centric language, the ability to retrieve information within a context, and the ability consistently present this information through a human-like personality. In this paper, we explore chatbots' potential to recondition how a specific group of users interact with information, especially when the chatbots are purpose-built for the user group. This is done through reflection on the ongoing process of chatbot development at the University of Technology, Sydney (UTS) Library, incorporated with reflection on relevant literature and thus takes a narrative rather than empirical approach. We argue that chatbots can provide new library users, generally undergraduate students, with a sense of ease in using the library resources, while minimising the effects of library anxiety related to research, library databases and librarian services (McPherson, 2015; Shelmerdine, 2018). Most users are already familiar with chatbots in other contexts in their everyday life, using them for example to find items on their phone with Apple's Siri, search their computer with Window's Cortana, or navigate the internet with Ok Google or Amazon's Alexa.

In addition we explore how a library chatbot may act as a central point of support for undergraduate students as they begin tertiary study and seek out assignment help. Woven through this exploratory paper are excerpts of responses from a library chatbot currently being prototyped and tested at the University of Technology Sydney (UTS). For purposes of this paper, we call the chatbot Lib-bot, with a non-gendered voice. In this paper, the prototype conversation design illustrates the potential of embedding a chatbot into a student's online learning management system, such as Canvas or Blackboard, so that when students log into their learning management system, a message such as the below is either heard or read 
based on, for example, each student's preference of name, connected university system, and timetable. (these are functions that can and are already integrated into the Learning Management System but rarely used by students):

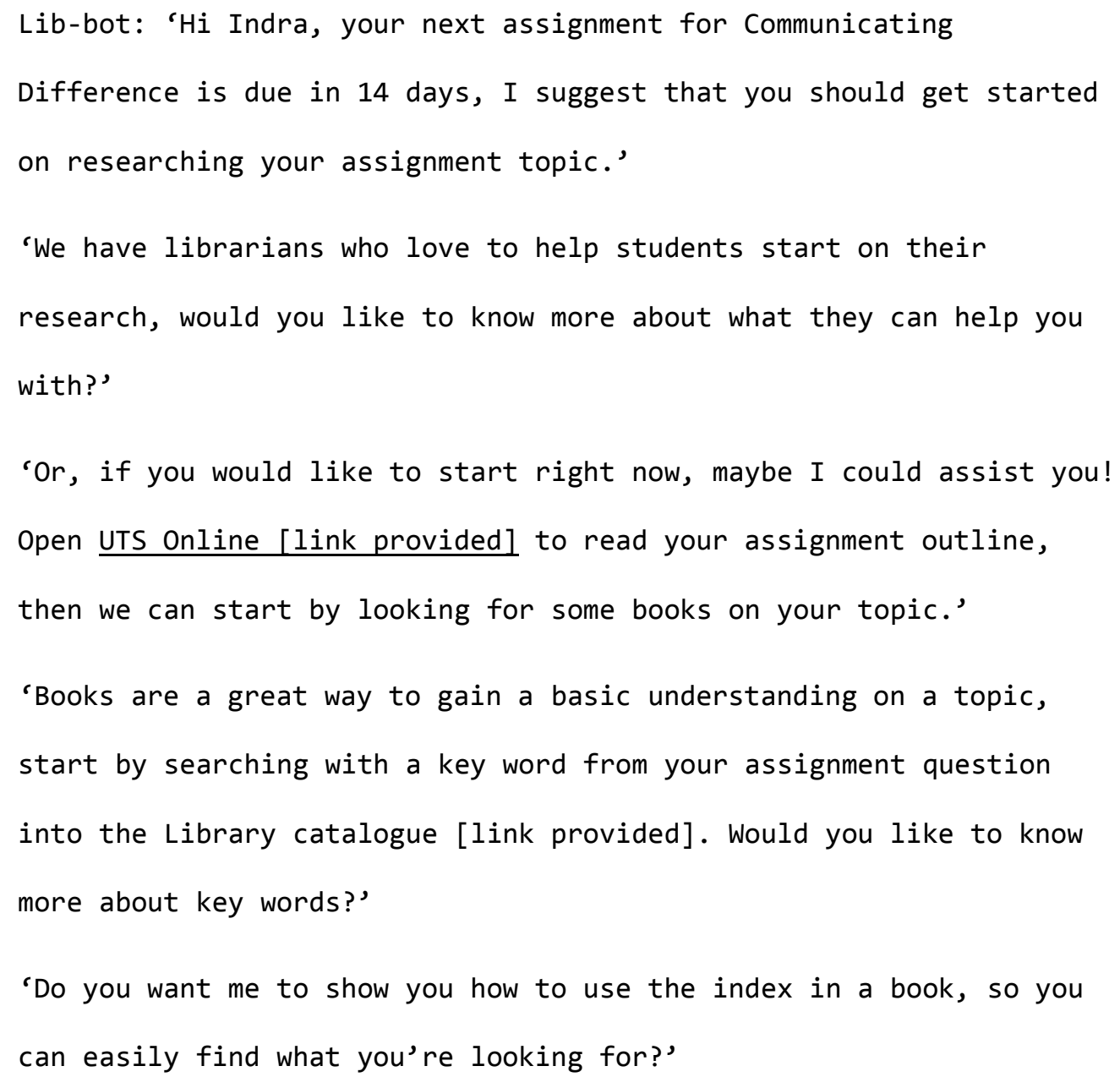

\section{CONTEXT}

\section{The library context}

Lack of transitional structures from high school to university can impact the attrition rate of undergraduate students, especially first-generation students who are 'less likely to have developed the skills in fulfilling the role of a self-directed and self-regulated learner that is expected of them in higher education' (Campbell \& Narayan, 2018, p. 47). University libraries engage with the first-year transition experience programs across many universities (Baik, Naylor \& Arkoudis, 2015), and also focus on delivering services that target new skills 
unique to tertiary learning such as research, referencing, digital literacy, ethics and selfdirected learning. The library at the University of Technology Sydney (UTS Library) has always strongly considered its library clients and their preferred methods of digesting university and library content when designing user-centric library services (Tiffen \& England 2011). In their paper on this library's proposed move to a new building in 2019, Booth, Scholfield and Tiffen (2012) defined UTS Library as a hub for knowledge, culture and collaboration. Library staff are encouraged to challenge library norms with playfulness, creativity and imagination (p. 41), where new experiences are enabled through sustainable practices and technology. An example of this is the creation of the Library Retrieval System (LRS) in 2014, which stores 450,000-plus books in an underground building (while 250,000 books still remain on the library's shelves), and uses autonomous technology for retrieval on request. This automation enabled the provision of more space for student utilities such as desks and computers, transforming UTS Library's purpose beyond a 'storehouse of books' (p. 42).

In this vision of the library setting, 'building social relationships with fellow students and teachers helps students feel comfortable in university life and provides sources of information and support during their study' (Tiffen \& England 2011, p.240). Despite the truth of this statement for our university where the focus has been on on-campus classes, an envisioned future transition to online degrees means there are fewer students on campus with whom to create these social relationships. To address this future issue, the idea of a chatbot was introduced by the Information Technology Division at UTS as a communicative technology that can mimic and recreate such social relationships to benefit students. Chatbots are available 24/7 and are accessible to anyone with an internet connection. Similar information can often be found on a website, but overload of content means that such information is lost within navigational bars or search results. With chatbots the information is 
presented in short conversational messages that are retrieved at a point of request, and can be available 24/7. They can also provide seeming conversational privacy, and hence can build trust, although that is a goal for future work rather than the focus of this paper, which simply explores the potential user interactions.

\section{Role of the Lib-bot}

The following section outlines the basic structure of how chatbots are constructed and operated based on the experience of the prototype chatbot being developed for the UTS Library, in which one of the authors was involved, and from the emerging literature. Chatbots often work on a logical sequence of information flow that determines their response to commonly asked questions. A student can open the pop-up chat window, enter a question, and within a second, they are matched to the response the chatbot finds most accurate. In chatbot development these questions are called utterances, which refers to the various ways in which an information need can be uttered within an isolated piece of dialogue. Using natural language processing (NLP) technology, the chatbot parses the sentence and tries to identify the goals of the user's utterance, and such goals are referred to as an intent (AbdulKader \& Woods, 2015). Intents are preassigned at least 5-10 sample utterances to help match the user's utterance to a goal. It is up to the developer of the bot to train the chatbot to finesse the finer context behind every question it is asked by preempting the utterances entered into a chatbot. So, no matter how many possiblities a chatbot may store, it is limited by the capacity and the creativity of the people who build, manage and train it. In the case of a library chatbot, librarians are the ones that best know their users, and hence the right people to collaborate with technologists on its development.

The amount of information the chatbot can store and the strength of its natural language program is key to their success, as 'there is a complicated development platform behind any chatbot which will only be as good as its knowledge base which maps a user's 
words into the most appropriate response.' (Abdul-Kader \& Woods, 2015, p.71). Thus, conversational bots aren't as scary as they sound; rather, they train and test the user to establish a more streamlined way to access the information they seek. At its core, a chatbot is a library of answers that are organised to respond to the goals of its user. Poor organisation of the library of responses will negatively impact the responses the chatbot chooses.

Depending on the context (or the chatbot vendor), the very design of chatbot responses can differ, even before they are customised for any library. There are a variety of chatbot types. For example, FAQ bots are chatbots that don't retain any memory of past conversations and are thus limited to a single question-and-response interaction. Guided conversation bots feed the client questions until they have satisfied their data quota; after acquiring the needed information they are then able to process a prescribed transaction. It can be expensive transitioning between types, so it is important when building a library chatbot to plan and consider the specific context (and vendor), and also to keep in mind that this manner of human-like conversation design is a new and developing domain in regard to chatbots.

When creating the chatbot's responses, it's important for the developer to be conscious of the chatbot's role in the journey of the user; who will the chatbot be to the listener? Will it simulate a salesperson; selling them on a product, a digital assistant. Will it be attentive to their requests (Woods, 2018, Smestad, 2018 and Cahn, 2017)? Can it simulate a librarian leading them to knowledge? UTS Library strives to be the central hub for knowledge, culture and collaboration and the first point of call (for student life at UTS. However, as pointed out by Booth, Schofield and Tiffen (2012), 'the library cannot provide this assistance alone, but partnerships with other support units can provide a seamless triagestyle service' (p.38). The chatbot as an interface could work as a digital triage system to direct undergraduate students to appropriate services by matching their questions to an intent. The chatbot can then match that intent to a solution, such as as a transactional response, a 
hyperlink to website content, a staffed service in the library, careers consultants, or academic writing tutors . In the following example, the chatbot reminds the student not only about an upcoming deadline, but also directs them to other academic writing support services at the university:

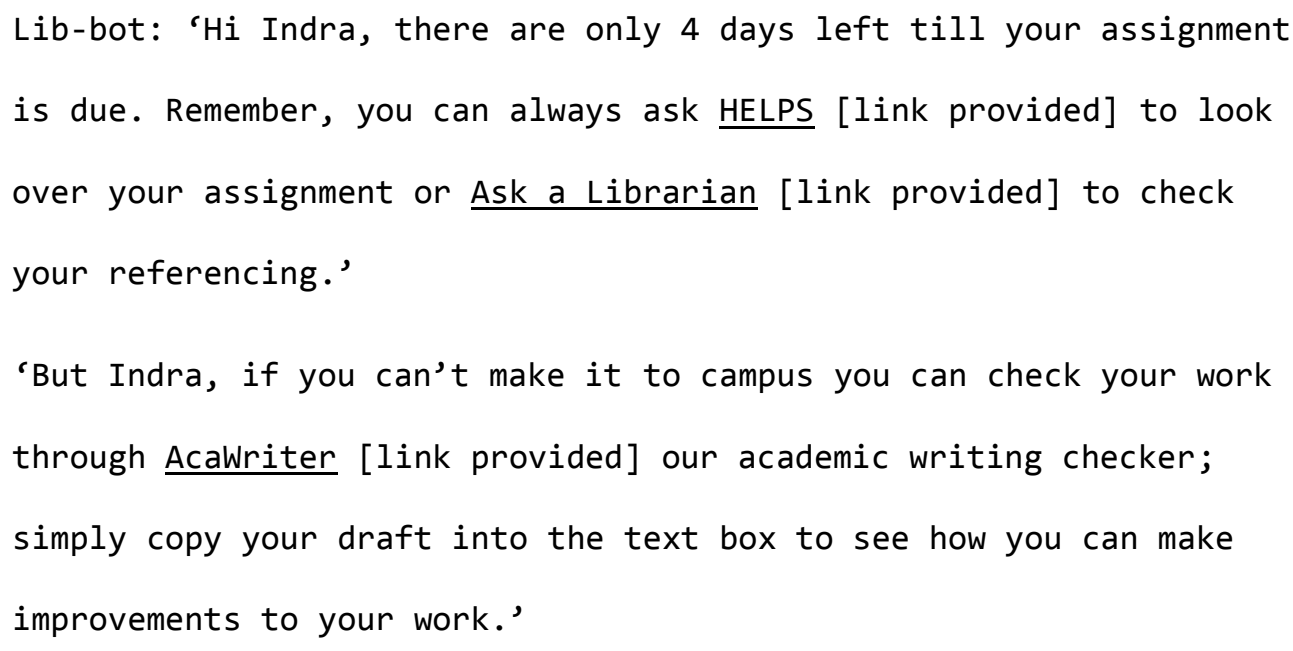

Chatbot availability can be force-limited to a certain demographic (university students and staff in our case), by logging in through a university's single sign-on process, and we can also provide the users with some level of personalisation and customisation. Leveraging this technology to a group of users that UTS Library interacts with daily means a closer understanding of the user can be applied in the development of the chatbot. With this, responses can be even more targeted towards certain student journeys and experiences. Undergraduates, always the newest users of the library, often exhibit the symptoms of library anxiety (McPherson, 2015; Shelmerdine, 2018); hence, a chatbot focused on their early entry into university offers an opportunity to condition how new students perceive research and library services. A closer look at the features of chatbots will highlight how they can be used to achieve this goal. 


\section{CHATBOTS IN LITERATURE AND PRACTICE}

\section{Conversing with technology}

'Today, I will teach you how to tell the database to give you what you want': we commonly resort to this phrase when teaching students and clients how to research at UTS Library. Whether it be at a library workshop, online chat or one-on-one consultation, client services librarians have found this simple explanation helps to empower the client's perception of an academic research experience. Due to the affordances of keywords in the storage and retrieval of information from databases, librarians are forced to ask UTS students, staff and researchers to abandon their natural language conventions and adopt more machinefriendly conventions such as Boolean logic in order to search the bibliographic databases.

It is not a difficult task, but the grammatical rules, sentence structure and standardised vocabulary of search strategies using Boolean logic tend to frustrate those who are not prepared for additional training on top of their already complicated coursework (McPherson, 2015; Swigon, 2011). Those students who dedicate time to learning to converse with a chatbot are rewarded with the promise of enjoyable conversations with multiple databases. When barriers to information are removed, students are rewarded (Meyers, Nathan \& Saxton, 2007) with accurate and relevant findings to incorporate into the writing phase of the assignment cycle.

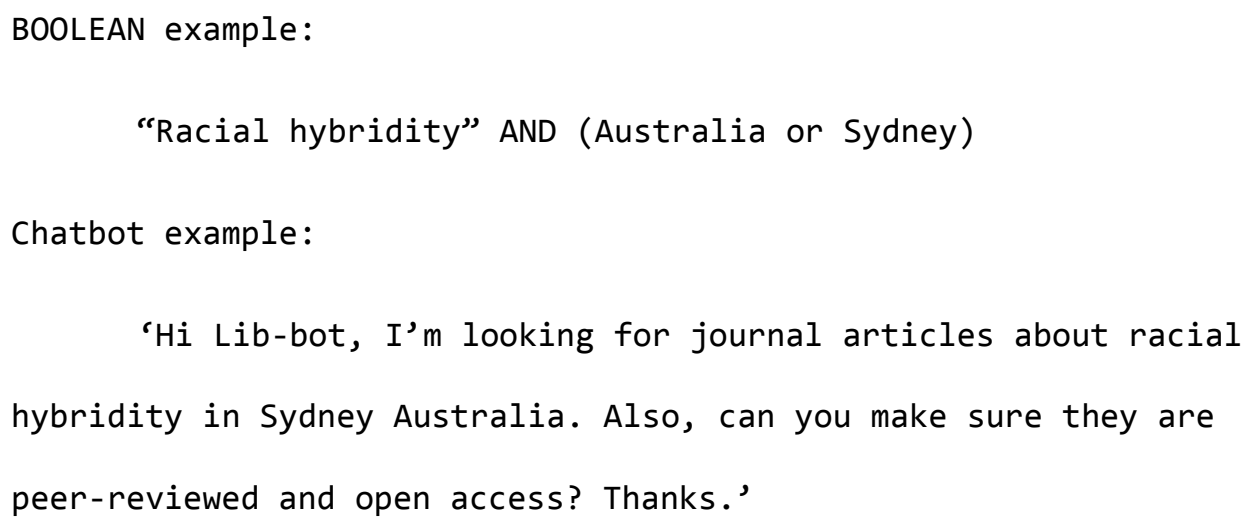


Learning languages gives us the ability to access new sources of information to help us produce better understandings (Mckie, 2018). To put this into perspective, imagine your frustration when visiting a country whose language you did not speak, or how difficult it would be to build or manipulate a website without learning a programming language such as HTML, CSS, or Java. Our competency with technical or machine languages determines our ability to make the most of our physical and digital environments. Amid an undergraduate's searching of library databases and catalogues, information barriers can lead the student to either minimal findings or an overload of irrelevant search results. A dissatisfactory research experience can lead to feelings of demotivation and disappointment, potentially manifesting in a shallow literature review, weak argument or, ultimately, plagiarism in university assessments. But what if our clients could naturally converse with their inherent language conventions and sentence structures intact?

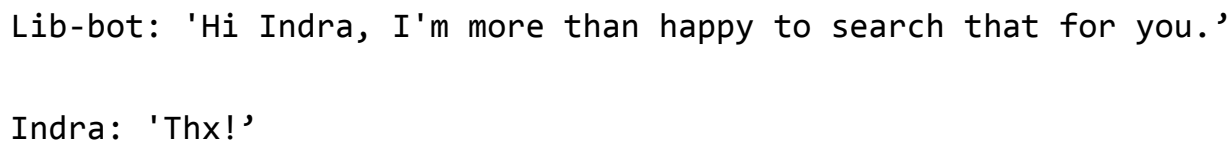

The age of the mobile phone has already well adapted the collective human consciousness to the quick and concise communication afforded through text messaging. During this process, there is always an underlying experience of interacting with another person. Due to their reliance on stored responses, conversational bots are like a game, a game where, 'the set of circumstances is going to be the same every time' (Turkle, 2005, p.88) and with 'practice, the performance rules become transparent' (p.89).

\section{Asking for information}

Library clients tend to seek information at a point of need, rather than proactively preparing by attending library workshops or by searching for online resources such as instructions, modules or videos (Jameson, Natal \& Napp, 2018). Stimulus, such as passing inspiration or the assignment's due date, is needed to coerce the individual towards initiating 
a search, as information seeking is intrinsically episodic (Prabha et al., 2007). A database is a symbolic form (Manovich, 2007) that follows no linear rule; items are catalogued and preserved based on standardised codes for retrieval. Due to the antinarrative affordances of databases (Manovich, 2007), items are stored as equals; in the database their history and context are erased, only to be re-deciphered by the researcher. A chatbot can mask this antinarrative attribute with a conversational tone and human-like voice.

Artificial intelligence already plays a large part in the decision-making process about how and what information is presented to the user. Algorithms are written to command the automated recovery of information to an intent or question, analogous to theme-based models of information retrieval. For example, 'until alphabetical organisation became popular a few centuries ago, most encyclopedias were organised thematically, with topics covered in a particular order' (Manovich, 2007, p.51-52). Take the most recognisable form of database organisation in academic research; 'most recent' -this makes sense to the student because humans have a very strong understanding of time, and what makes something new. Next, we can understand 'most popular,' the student is aware of the place in a large group of people, and the more a source is read, people are led to believe that it must be the most informative or reliable source (which is not always the case). Hence, it can be difficult for the user to comprehend the database's depiction of 'most relevant.' Without any formal training on the infrastructure of databases, the user cannot logically understand how the invisible algorithms of the database came to this conclusion. As a result 'transparent preference elicitation' was proposed by Herse et al. (2018) as a strategy to increase trust in human-robot interaction regarding recommender systems such as chatbots or traditional databases' graphical interfaces. Transparent preference elicitation involves explaining the agent's decision-making processes in information retrieval which may increase trust with computer recommender 
systems. This could be made possible through the chatbot's conversational style, for example:

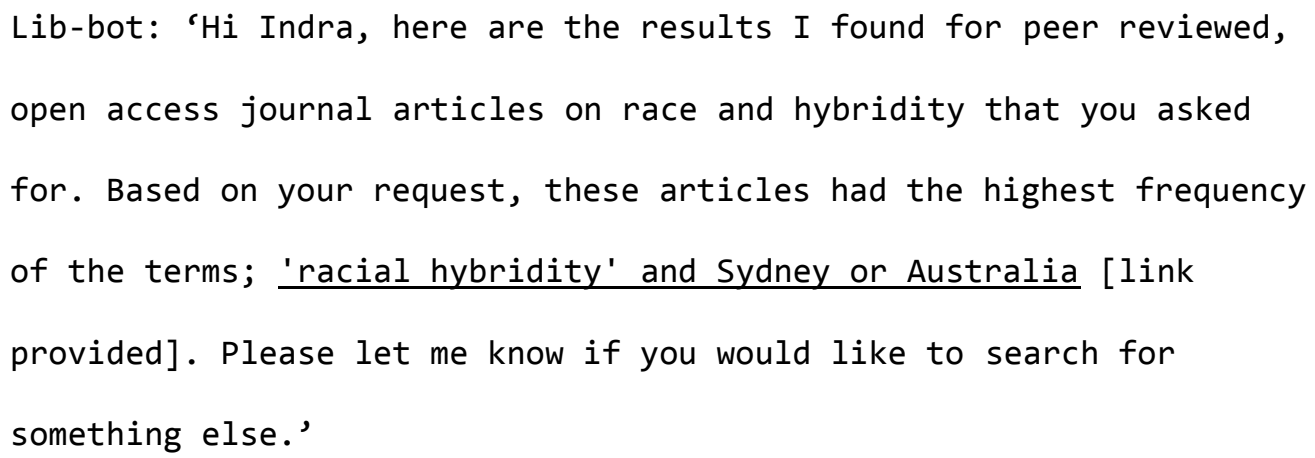

\section{Communicating with empathy}

Narrative is an enduring framework in which information is communicated in a linear sequence (Murray, 2003) using setting, tone, and characters to connect to audiences in empathetic manner. Today, we consume these narratives through verbal storytelling, film, music, art etc. We follow the characters in these stories and observe their motives, triumphs, and downfalls, and we are validated with a shared experience of the human condition (Contzen \& Alders, 2015). Narrative theory and psychology (Sengers, 2005, p.291; Murray, 2003) tell us that our minds retain knowledge better when it is framed in narrative. We have the capacity to tie memories to highly emotionally stimulating events, for example something or someone that made us laugh, cry or smile.

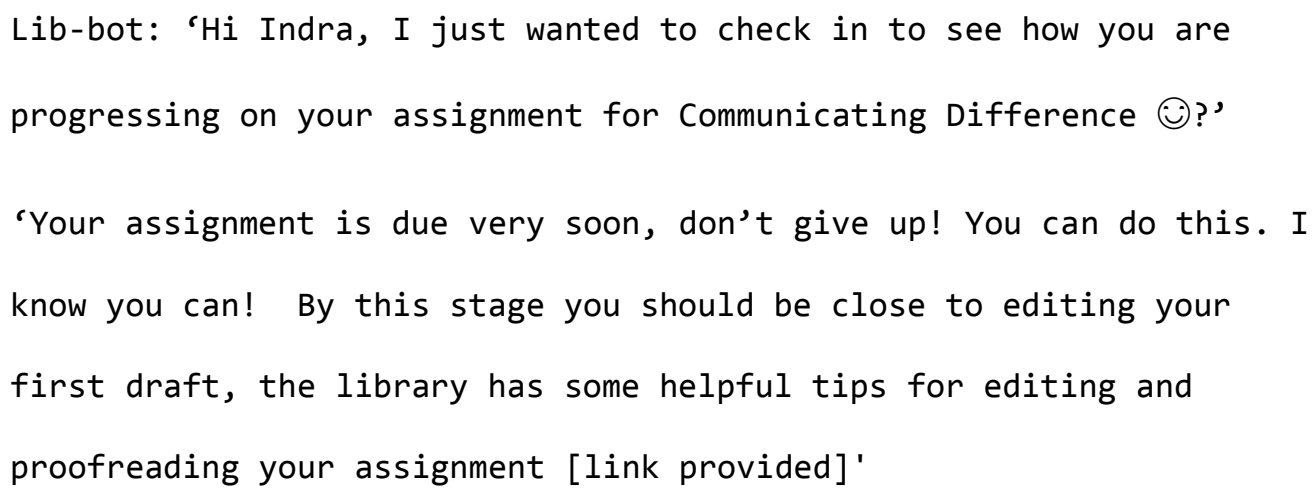

Arguably, it is the symbolic characterisation of the database as an objective entity that can either imbue the user with a sense of trust or alternatively, skepticism and distrust. The 
interface to the database has the power to skew the spectrum of trust or skepticism for the user. Hence, conversational interfaces must rely on the constitution of artificial personality to establish a consistent user experience. This user experience is dictated via the dynamic relationship between the "designed humanness" and perceived anthropomorphism in conversational user interface design (Smestad, 2018). When data is spoken into existence, either through a visual or audible form, personality is conjured by the human recipient, as voice 'is an index of the person or 'character' who is speaking' (Crisell, 1994, p.43). By designing an empathetic personality and social roles into our chatbots we create new characters to guide undergraduate students in their individual journeys through university.

\section{Reducing library anxiety}

Revealing our weaknesses to others by asking questions has been discovered as a precursor to library anxiety, where 'asking a research question in an academic library reveals much about a person's education level and research experience' (McAfee, 2018, p.237). Chatbots can step in to intervene here by reducing stress, if designed in a user-friendly, interactive way, especially as most undergraduate students at our university are already very familiar with chatbots in other contexts in their everyday life.

Personality and social roles are emulated and replicated to build trust with users, which is devised through the careful scripting of culturally and socially bound dialogue. As Barker and Galansinski articulated, 'to speak is to take up a position and to be subjected to the regulatory power of that discourse' (2001, p.13). Our Lib-bot could ultimately bring a new sense of belonging for new undergraduate students, where the student's success in university is followed and narrated by their personal bot friend. 


\section{DISCUSSION AND CONCLUSION}

Following our conversation design prototype with our library chatbot Lib-bot so far, we have been able to skip through multiple pages of search bars and filters and have also been able to link the key search terms in a linear manner with the student's other university systems such as subjects enrolled. The chatbot remembers the students' name, as single signon login is common practice for our university. When designed for the user, chatbots have the potential to deliver key information and services to our bottom-line consumers who may miss our other engagement strategies while browsing social media, their physical environment, and formal websites. Instead of relying on students to discover library workshops and services, we can directly message the students at different points of need during their assignment cycles. Students constantly ask for more feedback and personalised advice from their front-line contacts at the university - their tutors and lecturers with whom they have a personal relationship. Student cohorts continue to grow, and to cater to them, automated feedback methods such as interactive voice responses are becoming the norm, but these are often quite clinical in that they provide canned responses to menu choices based on the digits one enters on a phone. A customised and personalised chatbot can make that experience a lot more interactive and pleasurable, leaving the students with a good experience in their library interactions.

\section{Future Work}

It is important to keep in mind that students' research skills grow as the undergraduate matures through their academic career. This type of conversational searching may not suit more advanced researchers conducting systematic reviews or meta-analyses, but the chatbot can be coded with prompts and reminders about key referencing resources and services. We also need to remember that no matter how invincible we perceive automated bots to be, they are tied to the capacity and the creativity of the people who build them, the amount of 
information they can store, and the structural strength of their knowledge base (Abdul-Kader \& Woods, 2015, p.71).

In 2004, Rose and Levinson asked, 'what difference would it make if the search engine knew the user's goal?' With chatbots as an imminent interface, the following question could be posed, 'what happens when the search engine knows the user's goal and is designed to tailor the experience towards achieving it?' Without being intrusive or encroaching on privacy, information professionals need to be adapting emerging technologies to innovate, improve and support library services. However, mindfulness of users' experiences is essential to ensure sustainable and successful digital solutions, as 'modern design thinkers should concentrate on designing life instead of just new artefacts' (Saariluoma, Canas \& Leikas, 2016, p.5).

User studies are currently being conducted to examine how this chatbot-based model of using academic libraries can enhance students' research skills and learning experience. The development of the bot is on-going and is part of a series of chatbot projects run by the Information and Technology Division at UTS.

\section{Acknowledgements}

We would like to acknowledge the Gadigal People of the Eora Nation and the Boorooberongal People of the Dharug Nation upon whose ancestral lands UTS now stands. We would also like to pay respect to the Elders both past and present, acknowledging them as the traditional custodians of knowledge for these lands. We also would like to thank our colleagues at the University Library and the Information Technology Division at the University of Technology Sydney. This research is supported by Australian Government 
Research Training Program Scholarship (RTPS) and the University of Technology Sydney Doctoral Scholarship. 


\section{REFERENCE LIST}

Abdul-Kader, S. \& Woods, J. (2015). Survey on chatbot design techniques in speech conversation systems, International Journal of Advanced Computer Science and Applications, 6(7), 72-80.

Barker, C. \& Galansinski, D. (2001). Language, culture, discourse, in C. Barker \& D. Galansinski (eds.), Cultural studies and discourse Analysis: A dialogue on language and identity, London, UK: Sage.

Baik, C., Naylor, R., \& Arkoudis, S., (2015), The first year experience in Australian universities: findings from two decades, 1994-2014 (report). Melbourne, VIC: Melbourne Centre for the Study of Higher Education.

Booth, M., Schofield, S. \& Tiffen, B., (2012), 'Change and our future at UTS Library: it's not just about technology', Australian Academic \& Research Libraries, 43(1), 32-45.

Cahn, J. (2017). Chatbot: Architecture, design, \& development (Senior thesis), School of Engineering and Applied Science, University of Pennsylvania.

Campbell, K. \& Narayan, B. (2018). First-generation tertiary students: access is not the same as support, The International Journal of Innovation, Creativity and Change, 3(3), 4459.

Contzen, E., \& Alders, M. (2015). Collective experience in narrative: conclusions and proposals, Narrative, 23(2), 226-229.

Crisell, A. (1994). Radio signs and Codes: Understanding Radio (2nd ed) London; New York: Routledge.

Herse, S., Vitale, J., Tonkin, M., Ebrahimian, D., Ojha, S., Johnston, B., Judge, W. and Williams, M.A., (2018). Do you trust me, blindly? Factors influencing trust towards a robot recommender system, 27th IEEE International Symposium on Robot and Human Interactive Communication (pp.7-14), China: IEEE.

Jameson, J., Natal, G. \& Napp, J. (2018). Evolving and enduring patterns surrounding student usage and perceptions of academic library reference services, College \& Research Libraries, in press.

Manovich, L. (2007). Database as symbolic form. In V. Vesna (ed.), Database aesthetics (pp.39-60), Minneapolis: Minnesota University Press.

McAfee, E. (2018). Shame: the emotional basis of library anxiety, College \& Research Libraries, 79(2), 237-256.

Mckie, I. (2018). Navigating mixedness: the information behaviours and lived experiences of biracial youth in Australia, Cosmopolitan Civil Societies: An Interdisciplinary Journal, 10(2), 67-85.

McPherson, M. (2015). Library anxiety among university students: a survey, International Federation of Library Associations and Institutions, 41(4), 317-325.

Meyers, E.M., Nathan, L.P. \& Saxton, M.L., (2007), 'Barriers to information seeking in school libraries: conflicts in perceptions and practice', Information Research, 11(2), $1 \mathrm{p}$.

Murray, M. (2003). Narrative psychology. In J. Smith (ed.), Qualitative psychology: a practical guide to research methods (pp.111-131), London: Sage Publications.

Prabha, C., Silipigni Connaway, L., Olszewski, L. \& Jenkins, L.R. (2007). What is enough? Satisficing information needs, Journal of Documentation, 63(1), 74-89.

Rose, D. \& Levinson, D. (2003). Understanding user goals in web search, in Proceedings of the $13^{\text {th }}$ international conference on World Wide Web (pp.13-19), New York: ACM.

Saariluoma, P., Canas, J.I. Leikas, J. (2016). Designing for life: a human perspective on technology development, London: Palgrave Macmillan. 
Sengers, P. (2005) The engineering of experience. In M. Blythe, K. Overbeeke, A. Monk, P. Wright (ed.), Funology: from usability to enjoyment (pp.19-29), New York: Kluwer Academic Publishers.

Shelmerdine, A.J. (2018). Library anxiety: stories, theories and possible solutions, Journal of the Australian Library and Information Association, 67(4), 343-352.

Smestad, T. (2018), Personality matters! Improving the user experience of chatbot interfaces, thesis, Norwegian University of Science and Technology, Department of Design, Norway.

Swigon, M. (2011). Information barriers in libraries: types, typologies and Polish empirical studies, Library Management, 32(6), 475-484.

Tiffen, B. \& England, A., (2011), 'Engaging with clients and personalising services at UTS Library: measuring the value for libraries and their clients', The Australian Library Journal, 60(3), 237-247.

Turkle, S. 2005, The second self: computers and the human spirit, $20^{\text {th }}$ anniversary eds, Cambridge, Massachusetts: MIT Press.

Wood, E. \& Almeida, J. (2017). If we charge them, will they come? Reference \& User Services Quarterly, 56(3), 158-161.

Woods, H. (2018). Asking more of Siri and Alexa: feminine persona in service of surveillance capitalism, Critical Studies in Media Communication, 35(4), 334-349. 